Research Article

\title{
Recycling of Waste Mixed Plastics Blends (PE/PP)
}

\author{
Eddie Gazo Hanna
}

Mechanical engineering department, Beirut Arab University, P.O. Box 115020, Riad El Solh, Beirut, Lebanon

Received 27 December 2018; Accepted 20 May 2019

\begin{abstract}
Garbage and waste became lately one of the biggest problem in Lebanon since the population increased to 6 million in 2019. This project aim is to develop an efficient method to reuse plastic packages that are used in our daily life. A machine is designed to recycle and mix the Polypropylene (PP) and the Polyethylene (PE), commonly used in packages. Different specimens of these polymers were prepared by varying the percentage of each component. The propylene diene monomer (EPDM) was used as a compatiblizer in the blends preparation. Mechanical properties were selected to estimate the compatibilization efficiency of EPDM. Addition of EPDM to PE/PP blends improved mechanical properties, especially the elongation at break.
\end{abstract}

Keywords: Recycling, Mixed Plastic Waste, Tensile Properties, Flexural Properties, Injection Molding.

\section{Introduction}

In a modern society, it's impossible to imagine life without plastics. Plastics are found in diverse fields as packaging, construction, medicine, household appliances, electronics, automotive and aerospace components. The purpose behind its success in supplanting conventional materials, for example, wood, glass and metal's in such a differing scope of utilizations, is the capacity to adjust its properties to meet a vast array of designer's needs.

The management of plastics waste is one of the significant issues confronting present day society. According to a study made by the United States Environmental Protection Agency, it is stated that plastic made up $12 \%$ of the 254 million tons of waste generated in 2015 [1]. That's more than 30 million tons of plastic in one year. Some reports state plastic materials can take hundreds of years to break down in a landfill. And, for every 1 ton of plastic that's recycled, reports estimate that 7 yards of landfill space is saved.

Lebanon produces 2.04 million tons of Municipal Solid Waste (MSW) every year and every individual creates roughly around 0.8 to $1.2 \mathrm{~kg}$ per day. The MSW is made out of $16 \%$ paper; $11.5 \%$ plastic; $5.5 \%$ Metal; $3.5 \%$ glass and $52.5 \%$ natural waste [2]. All of the MSW produced is gathered by public or private haulers; however, management varies from one region to another: $8 \%$ is recycled, $15 \%$ is composted, $51 \%$ is landfilled and $26 \%$ is discarded in open dumps [2]

In the aim of replacing open dumping, Lebanon should adopt a good and efficient way of solid waste management. It should be based on recycling and preventing waste. This work will introduce a new technique for producing plastic parts from thermoplastic waste. The mixed plastics waste can be recycled in the form of blends [3] and as most blends

*E-mail address: eddie.hanna@live.com

ISSN: 1791-2377 @ 2019 Eastern Macedonia and Thrace Institute of Technology. All rights reserved. doi:10.25103/jestr.122.12 of incompatible polymers are frequently very brittle, and need to be compatibilized with an additive [4], the first part of this research consists on the design of a new plastic injection machine that will first, mix two incompatible blends and secondly, inject the plastic using a single-screw plasticating system which is commonly used for injection molding. The second goal of this study is to work on selecting the appropriate blend made with of the construction and household mixed plastic waste available in local landfills and the selection of a good additive that may give the blend more ductility.

\section{Design of a Recycled Plastic Injection Molding Machine}

\subsection{Introduction}

A basic injection molding machine is composed of the following parts [5] [6], as seen in Figure 1:

- The hopper holding the thermoplastic material, provided in the form of small pellets. By gravity these pellets are fed inside the barrel and the screw assembly.

- The barrel supporting the screw. It may be heated if the injected plastic needs higher temperature to melt.

- The screw responsible of melting and injecting the material into the mold.

- The nozzle connecting the barrel to the mold.

- The mold system

In order to use post-consumer plastic blends in the manufacturing of new plastic parts, the next step of this research consists on designing a two stage machine with a single plasticating screw and a vertical-mixing system replacing the ordinary hopper. 


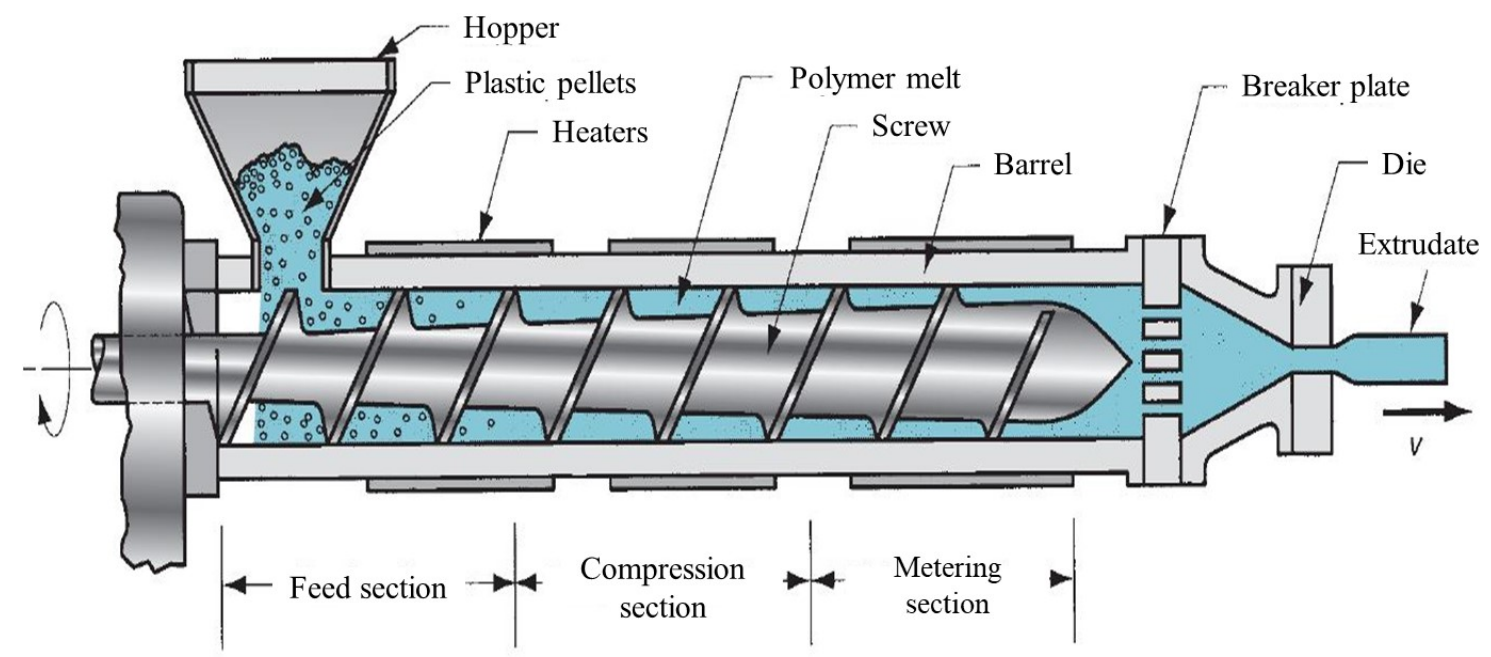

Fig. 1. Basic injection molding machine for thermoplastics

\subsection{Mixing Process}

The process starts in the vertical-mixer (Figure 2) wherein the cleaned and crushed waste materials with the appropriate ratios, are mixed at high speed using a paddle. Typically, feedstocks are added to the blends such as EPDM in order to improve the mechanical and chemical properties.

The paddle rotates at a lower speed of $85 \mathrm{rpm}$ using a 2.2 $\mathrm{KW}$ power electrical motor. The mixer capacity is $25 \mathrm{Kg}$ and the mixing time is between 5 and 15 minutes. The mixed material is then conveyed, in form of small pellets, through a connecting tube from the material outlet to the plasticating screw. This screw is rotated to melt the mixed material and to accumulate molten plastic in front of the screw. When the required amount of molten plastic is accumulated, the injection process begins.
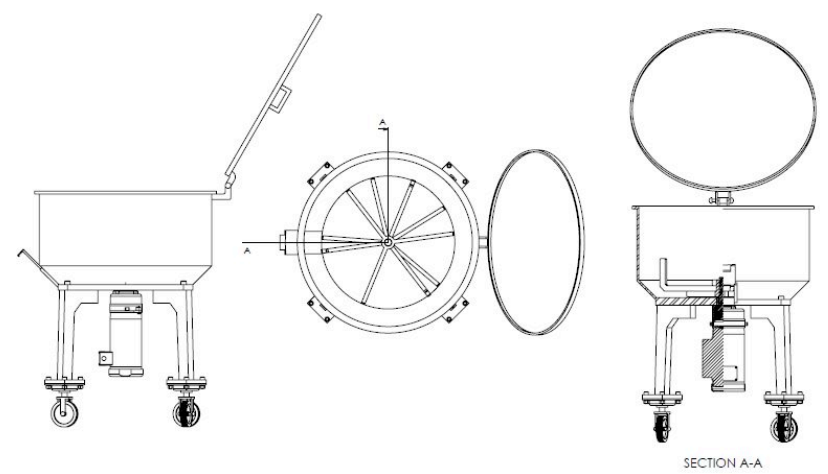

Fig. 2. Diagram of the Mixer

\subsection{Plasticating System}

A plasticating system includes the barrel, a screw with three important zones, the shank, a drive motor to rotate the screw and a non-return valve located at the tip of the screw.

The screw is made of three sections: the conveying or feed section, the melting section and the metering section.

The conveying section of the screw is designed with a constant depth which is about one third of the overall length of the screw. The feed channel is generally 2 to 6 times deeper than the metering section of the screw, and generally has constant depth over its entire length. The solids conveying section of the screw must be able to provide resin at a rate fast enough and under pressure to keep the melting and metering sections full of resin. If the solids conveying section is rate limiting, then downstream sections of the screw will be partially filled.
Right after the solids conveying section, we have a transition section where the melting process occurs. The maximum plasticating rate for a screw is typically limited by its melting capacity. A specific motor torque must be insured in order to stand high screw rotational speeds because at low screw speed a discharge free of solid polymer fragments will happens. As the screw speed increase, a variety of defects in the molded parts will appear.

Next step is the metering section where the material is pushed and pumped through a non-return valve and the material is collected in the front of the screw for the next injection cycle. As the material is collected, the screw has to retract to provide additional volume for the next injection cycle.

\subsection{The extruder screw}

The extruder screw is designed with an 18:1 length to diameter ratio $\left(L / D_{b}\right)$. To achieve this ratio, the selected barrel diameter and the flighted length of the screw are respectively $77 \mathrm{~mm}$ and $1300 \mathrm{~mm}$. To insure a smooth flow of the molten resin inside the screw a square pitch of $17.66^{\circ}$ helix angle is selected with a pitch of $60 \mathrm{~mm}$. The compression ratio is calculated at 1.8 , while the compression rate is 0.018 . The specifications and calculated geometric parameters values of the screw are provided in Table 1 along with the equations used for the calculations.

Table 1. Significant Screw Dimensions

\begin{tabular}{|c|c|c|c|}
\hline & $\begin{array}{l}\text { Nomen- } \\
\text { clature }\end{array}$ & Equation & Value \\
\hline $\begin{array}{c}\text { Barrel } \\
\text { diameter }\end{array}$ & $D_{b}$ & & $77 \mathrm{~mm}$ \\
\hline $\begin{array}{l}\text { Overall } \\
\text { length }\end{array}$ & $L$ & & $\begin{array}{l}1388 \\
\mathrm{~mm}\end{array}$ \\
\hline $\begin{array}{l}\text { Flight } \\
\text { length }\end{array}$ & F.L. & & $\begin{array}{l}1300 \\
\mathrm{~mm}\end{array}$ \\
\hline $\begin{array}{l}\text { Feed } \\
\text { section } \\
\text { length }\end{array}$ & $L_{f}$ & $50 \%$ of the flight length & $\begin{array}{l}650 \\
\mathrm{~mm}\end{array}$ \\
\hline $\begin{array}{l}\text { Transition } \\
\text { section } \\
\text { length }\end{array}$ & $L_{t}$ & $25 \%$ of the flight length & $\begin{array}{l}325 \\
\mathrm{~mm}\end{array}$ \\
\hline $\begin{array}{l}\text { Metering } \\
\text { section } \\
\text { length }\end{array}$ & $L_{m}$ & $25 \%$ of the flight length & $\begin{array}{l}325 \\
\mathrm{~mm}\end{array}$ \\
\hline $\begin{array}{l}\text { Flight } \\
\text { width }\end{array}$ & $W_{F L T}$ & $10 \%$ of $D_{b}$ & $\begin{array}{r}7.7 \\
\mathrm{~mm}\end{array}$ \\
\hline Lead length & $s$ & $0.8 \times D_{b}$ to $1.3 \times D_{b}$ & $77 \mathrm{~mm}$ \\
\hline
\end{tabular}




\begin{tabular}{|c|c|c|c|}
\hline $\begin{array}{l}\text { Flight } \\
\text { clearance }\end{array}$ & $\delta_{\text {FLT }}$ & $0.001 \times D_{b}$ & $\begin{array}{c}0.077 \\
\mathrm{~mm}\end{array}$ \\
\hline $\begin{array}{l}\text { Metering } \\
\text { channel } \\
\text { depth }\end{array}$ & $H$ & $0.03 \times D_{b}$ to $0.1 \times D_{b}$ & $\begin{array}{l}7.5 \\
\mathrm{~mm}\end{array}$ \\
\hline $\begin{array}{l}\text { Feed } \\
\text { channel } \\
\text { depth }\end{array}$ & $H_{f}$ & & $\begin{array}{l}13.5 \\
\mathrm{~mm}\end{array}$ \\
\hline $\begin{array}{l}\text { Compres- } \\
\text { sion ratio }\end{array}$ & $C$ & $H_{f} / H$ & 1.8 \\
\hline $\begin{array}{l}\text { Helix angle } \\
\text { at the } \\
\text { barrel wall }\end{array}$ & $\theta_{b}$ & $\tan ^{-1} \frac{L}{\pi D_{b}}$ & $80.1^{\circ}$ \\
\hline Helix angle & $\phi$ & $\tan ^{-1} \frac{s}{\pi D_{b}}$ & $17.66^{\circ}$ \\
\hline $\begin{array}{l}\text { Compres- } \\
\text { sion rate }\end{array}$ & $R$ & $\frac{\left(H_{f}-H\right) \sin \left(\theta_{b}\right)}{L_{t}}$ & 0.018 \\
\hline $\begin{array}{l}\text { Speed of } \\
\text { the screw } \\
\text { Bulk }\end{array}$ & $N$ & & $\begin{array}{l}100 \\
\text { rpm }\end{array}$ \\
\hline $\begin{array}{l}\text { density of } \\
\text { the } \\
\text { 30PE/70PP }\end{array}$ & $\rho_{0}$ & Assumption & $\begin{array}{c}400 \\
\mathrm{Kg} / \mathrm{m}^{3}\end{array}$ \\
\hline $\begin{array}{l}\text { Conveying } \\
\text { efficiency }\end{array}$ & $\eta_{F}$ & Assumption & 0.18 \\
\hline $\begin{array}{l}\text { Solid } \\
\text { conveying } \\
\text { rate }\end{array}$ & $G$ & $60 \cdot \rho_{0} \cdot N \cdot \eta_{F} \cdot \pi^{2} \cdot H \cdot D_{b}\left(D_{i}\right.$ & $\begin{array}{c}50 \\
\mathrm{Kg} / \mathrm{h}\end{array}$ \\
\hline
\end{tabular}

The solid conveying rate is calculated using the following empirical equation that provides good results in practice [7]:

$$
\begin{aligned}
& G=60 \cdot \rho_{0} \cdot N \cdot \eta_{F} \cdot \pi \cdot H \cdot D_{b} * \\
& *\left(D_{b}-H\right) \frac{W}{W+W_{F L T}} \sin \phi \cdot \cos \phi
\end{aligned}
$$

This equation shows that this rate is related to the conveying efficiency of the resin, the bulk density, the feed depth, the screw speed, the channel width, the flight width and the helix angle.

For pure PP and pure PE, the conveying efficiency are respectively 0.44 and 0.25 , and the bulk densities are respectively 480 and $560 \mathrm{~kg} / \mathrm{m}^{3}$. Since these parameters are missing for a polymer made of a mixture of these two polymers, an assumption has been made based on the values of the pure materials. The chosen parameters (Table 1) allow to design the screw with a minimum throughput of $50 \mathrm{~kg} / \mathrm{hr}$.

The diagram of the new Mixing-Injection molding machine is shown in Figure 3.

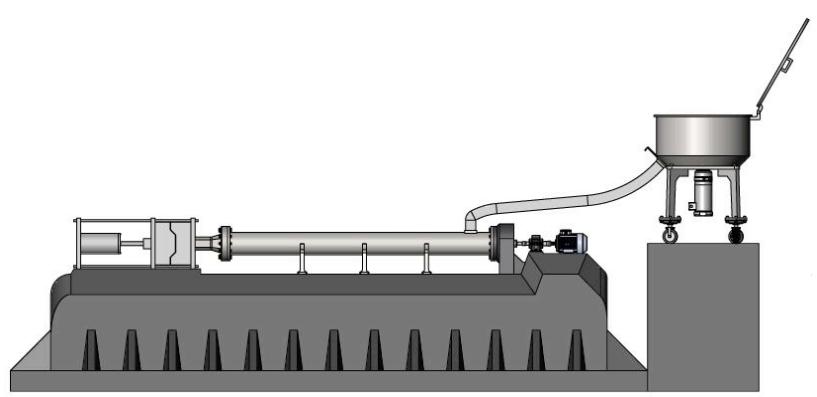

Fig. 3. Diagram the Mixing-Injection Machine

\section{Materials and Methods}

Polymer blends are acquired by blending no less than two macromolecular substances, polymers or copolymers, in which the ingredient content is over $2 \mathrm{wt} \%$ [8] [9]. The mechanical properties of the blends rely upon the phase morphology and the component proportions. These properties can be manipulated according to the end use by correct selection of the component polymers [10].

$\mathrm{PP}$ is commonly found in MSW, and has good mechanical properties, heat resistance, simplicity of handling, and full recyclability. Its greatest disadvantage is low impact strength, which can be enhanced using a good mixing technique, reason for selecting PE to blend with it. Generally, polymer blends are classified into either miscible (homogenous) or immiscible (heterogeneous) blends.

According to previous studies, PP and PE blends are heterogeneous [11] [12] [13]. Constrained miscibility between these two materials decreases the mechanical properties of the compounds [14]. To enhance the compatibility between the PP and PE, a compatibilizer can be included [12] [15]. Compatibilizers are regularly used as added substances to enhance the compatibility of immiscible polymers and thus improve the morphology and resulting properties of the blend.

Compatibilization is a vague notion that represent every action done to a mixture in order to improve its properties. Although it has a critical effect on the properties of the mixture, the comptabilization principal objective is to control the morphology of the mixture. This being said, the principal effect of the comptabilization is to reduce the interfacial tension to facilitate the dispersion; to stabilize the morphology of the mixture so that its evolution will be avoided during its transformation steps and finally to increase the adhesion between the solid state in order to improve its mechanical properties. Previous studies [8] [16] showed that the addition of EPDM improves the elongation at break and the impact strength of PE/PP blends.

Our work is focused on the improvement of the compatibility between PP and PE with the addition of EPDM. The impact was evaluated on the mechanical properties.

\subsection{Sources of materials and samples manufacturing}

Polymer blends of PE/PP, with and without EPDM, were produced from household blended plastic waste. The gathered material was sorted in the research center and then crushed using a size reduction crusher. Two quantities, $4 \mathrm{~g}$ and $6 \mathrm{~g}$, of EPDM were added to PP/PE blends. These samples were compared with pure $\mathrm{PP}$ and $\mathrm{PE}$, as well as $\mathrm{PP} / \mathrm{PE}$ blends with different proportions. The pure PP, density 0.9 $\mathrm{g} / \mathrm{cm}^{3}$, melt temperature $152^{\circ} \mathrm{C}$ and melt mass flow rate 45 $\mathrm{g} / 10 \mathrm{~min}$, and the pure PE, density approximately $0.95 \mathrm{~g} / \mathrm{cm}^{3}$ and melt mass flow rate $8 \mathrm{~g} / 10 \mathrm{~min}$, were supplied by Dalian Great Fortune Chemical Co., China.

\subsection{Preparation of the specimens}

Samples of pure polymers and blends of PE/PP with and without a compatibilizer were prepared using the designed extruder. After the extrusion, the specimens were prepared by injection molding at $220^{\circ} \mathrm{C}$, the injection rate of 150 $\mathrm{mm} / \mathrm{s}$, and the mold temperature of $40^{\circ} \mathrm{C}$. Two different amounts ( 4 and $6 \mathrm{~g}$ ) of EPDM were added to PE/PP blends. 


\subsection{Mechanical Properties}

\subsubsection{Tensile Test}

The measurements of tensile properties were done according to the ISO 527-2 standard test on a Zwick machine at a cross head speed of $50 \mathrm{~mm} / \mathrm{min}$. 5 specimens were tested for each type of blend and the average values were reported. A blend containing $30 \mathrm{~g}$ of Polyethylene and $70 \mathrm{~g}$ of Polypropylene, has the following notation: $30 \mathrm{PE} / 70 \mathrm{PP}$.

\section{Results and discussion}

Results showed that highest tensile strength of $35 \mathrm{MPa}$ is obtained for pure PP, whereas pure PE had only $12 \mathrm{MPa}$.

The measured tensile strength for different mixed plastic waste samples with different ratios are represented in Figure 4. According to the results, the virgin PP sample had significantly higher tensile properties compared with samples made from recycled plastics. This is mainly due to the incompatibility between PP and PE. When adding $4 \mathrm{~g}$ of EPDM to $\mathrm{PP} / \mathrm{PE}$ blends, results showed that the tensile strength was reduced, whereas addition of $6 \mathrm{~g}$ of EPDM did not have any effect on the tensile strength.

Figure 5 shows that the different blends had lower values of elongation at break compared with pure PE. The 30PE/70PP blend had the highest value among the other waste blends and on the other hand, results showed that the addition of EPDM to all PP/PE blends plays an important role and increases the elongation at break.

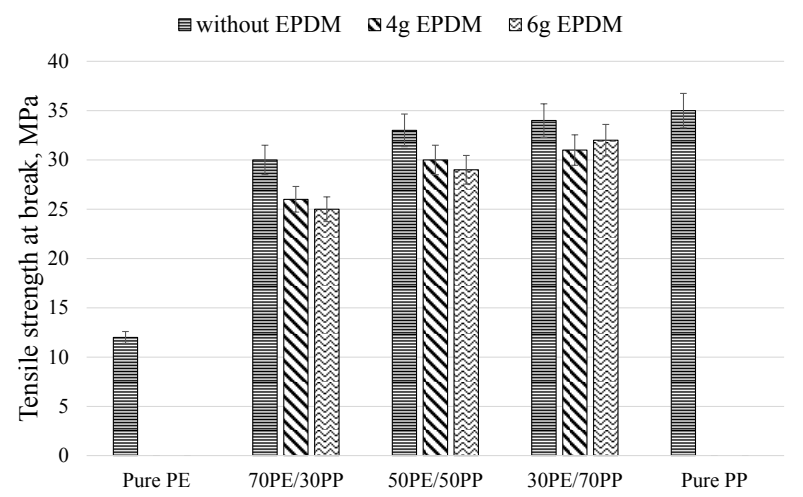

Fig. 4. Tensile strength at break

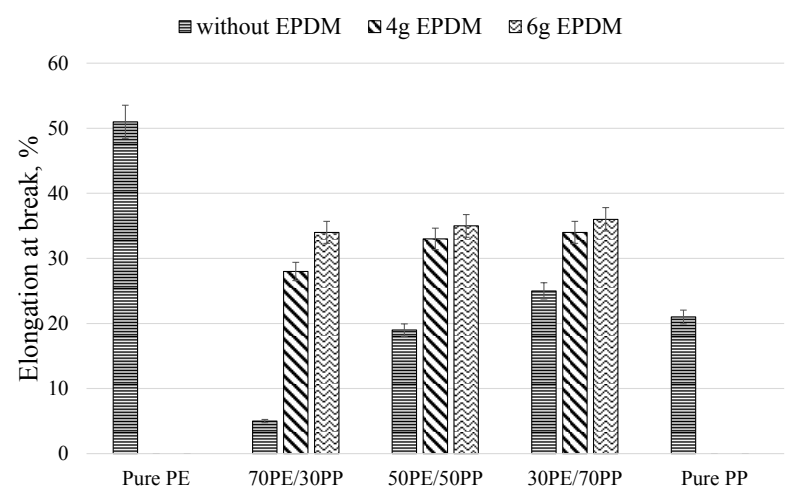

Fig. 5. Elongation at break

In all PE/PP blends, the addition of the compatibilizer improved the elongation at break, especially for 70PE/30PP and 30PE/70PP blends, compared with non-compatibilized blends. Increasing the amount of EPDM did not show significant change in the elongation at break, except for 70PE/30PP blend, which improved its elongation at break value for $20.42 \%$.
Different explanations of compatibilizing effect on mechanical properties can be discussed: Bartlett et al. [17] showed that the addition of an ethylene-propylene elastomer to PP/HDPE blends improves the ductility of these blends but with corresponding decrease in strength and modulus.

As well, Tchomakov et al. [18] concluded that elastomer addition decreases the tensile and flexural modulus in PP/HDPE/EPDM blends and improves impact strength.

According to Brostow et al. [19] and using the tensile measurements, the brittleness, $\mathrm{B}$, can be calculated with the following equation:

$$
B=\frac{1}{\left(\varepsilon_{b} E^{\prime}\right)}
$$

Where $\varepsilon_{b}$ and $E^{\prime}$ are respectively, the elongation at break and the storage modulus both measured at $25^{\circ} \mathrm{C}$.

The author showed that the addition of EPDM in all PP/LDPE blends decreases the $B$ values as shown in Table 2 .

Table 2. Values of Brittleness for PP/LDPE/EPDM blends.

\begin{tabular}{c|c|c|c}
\hline $\begin{array}{c}\text { PP/ LDPE/ } \\
\text { EPDM }\end{array}$ & $\boldsymbol{B}(\boldsymbol{\%} \mathbf{P a})$ & $\boldsymbol{\varepsilon}_{\boldsymbol{b} / \%}$ & $\boldsymbol{E} / \mathbf{P a}$ \\
\hline $100 / 0 / 0$ & 0.129 & 21.05 & $3.67 \mathrm{E}+09$ \\
$0 / 100 / 0$ & 0.308 & 48.40 & $0.67 \mathrm{E}+09$ \\
$80 / 20 / 0$ & 0.216 & 24.64 & $1.88 \mathrm{E}+09$ \\
$80 / 20 / 5$ & 0.152 & 36.88 & $1.78 \mathrm{E}+09$ \\
$80 / 20 / 7$ & 0.140 & 47.52 & $1.51 \mathrm{E}+09$ \\
$60 / 40 / 0$ & 0.887 & 7.67 & $1.47 \mathrm{E}+0.9$ \\
$60 / 40 / 5$ & 0.148 & 49.69 & $1.36 \mathrm{E}+09$ \\
$60 / 40 / 7$ & 0.156 & 48.59 & $1.32 \mathrm{E}+09$ \\
$40 / 60 / 0$ & 0.893 & 9.91 & $1.13 \mathrm{E}+09$ \\
$40 / 60 / 5$ & 0.209 & 46.73 & $1.02 \mathrm{E}+09$ \\
$40 / 60 / 7$ & 0.209 & 47.71 & $1.00 \mathrm{E}+09$ \\
$20 / 80 / 0$ & 0.299 & 33.77 & $0.99 \mathrm{E}+09$ \\
$20 / 80 / 5$ & 0.229 & 48.99 & $0.89 \mathrm{E}+09$ \\
$20 / 80 / 7$ & 0.250 & 49.27 & $0.81 \mathrm{E}+09$ \\
\hline
\end{tabular}

PP/LDPE 60/40 and 40/60 blends showed higher values of brittleness compared with pure PP and pure LDPE. This is in complete accordance with poor elongation at break values of PP/LDPE 60/40 and 40/60 blends, as explained earlier.

\subsection{Three Points Flexural Test}

The measurements of flexural properties were done according to the ISO 178:2010 standard test on the same Zwick machine. 5 specimens were tested for each type of blend and the average values were reported. This type of testing requires that the width of the specimen should be shorter than the two supports and the central loading edge, and parallelism within $\pm 0.2 \mathrm{~mm}$ must be respected. The specimens thickness is $3 \mathrm{~mm} \pm 0.1 \mathrm{~mm}$, the loading edge radius is $5 \mathrm{~mm}$ $\pm 0.1 \mathrm{~mm}$, and the supports radius is specified as $2 \mathrm{~mm} \pm 0.2$ $\mathrm{mm}$. The test speed is $2 \mathrm{~mm} / \mathrm{min}$.

As mentioned before, the higher amount of EPDM did not significantly change the mechanical properties of the blends. For this reason, the following curves will show different results for pure PE, pure PP and only PE/PP blends compatibilized with $4 \mathrm{~g}$ of EPDM.

From figure 6,7 , load vs deformation and the flexural stress vs flexural strain curves, it can be seen that the flexural strength reduces with the addition of polyethylene. The 
best flexural strength was obtained at the composition 30PE/70PP.

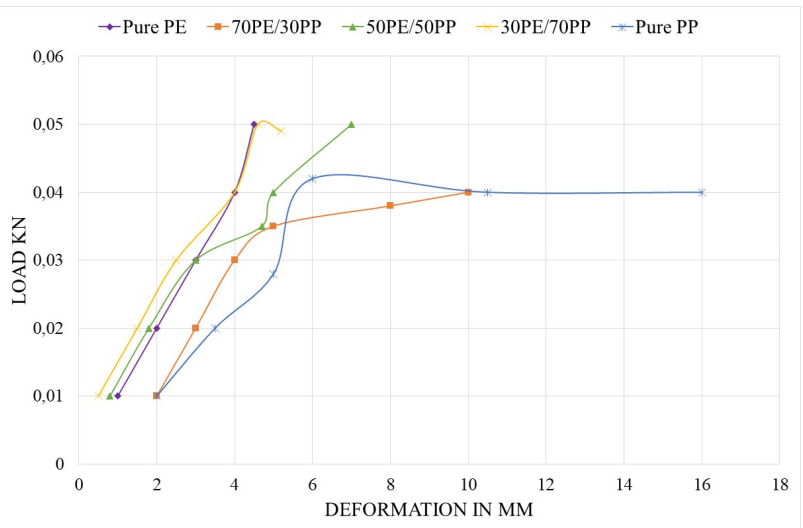

Fig. 6. Load vs Deformation for Flexural Test

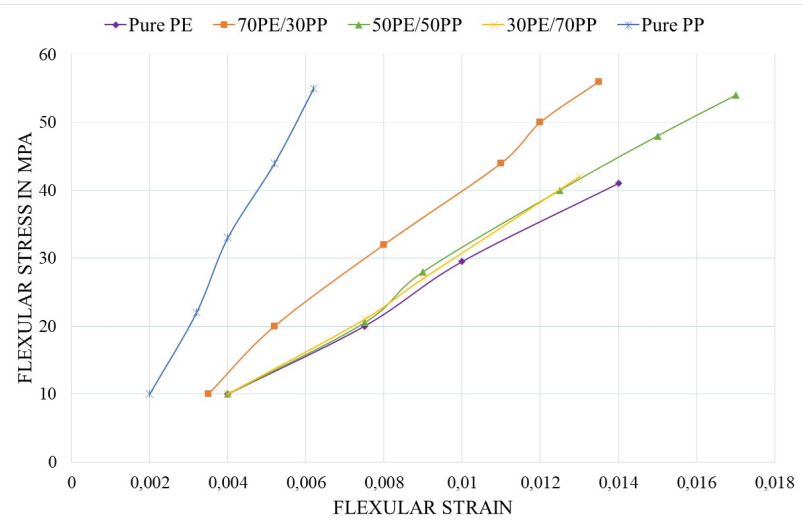

Fig. 7. Stress vs Strain curve of PE/PP blends

Figure 8 shows that the flexural modulus of the PE/PP blends decreases when the percentage of PE increases, which is ascribed for two reasons. One reason is that the crystallinity of the polypropylene PP reduces with the increase of the polyethylene PE content in any blend. The flexural modulus decreases when PP has a low crystallinity.

The second reason is that PE has lower flexural modulus compared to PP, thus, the higher of PE content, the lower flexural modulus the PE/PP blends have.

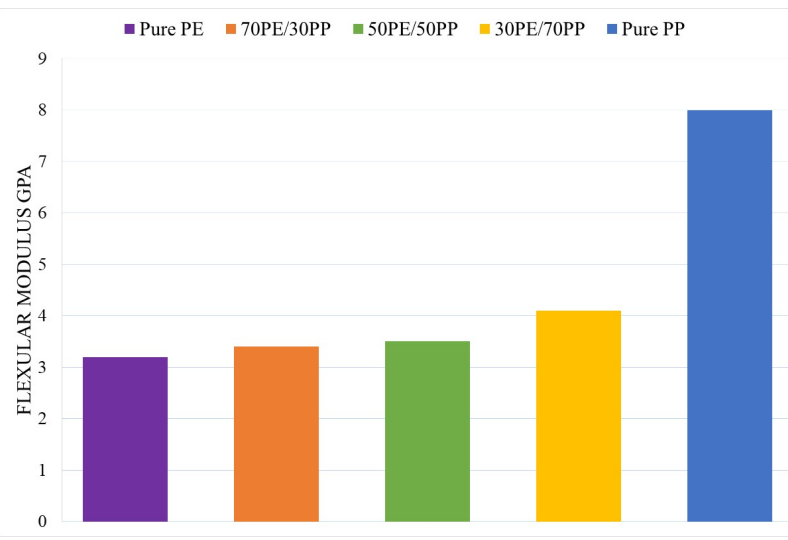

Fig. 8. Flexural Modulus of PE/PP blends

\section{Conclusion}

In this study, polypropylene (PP) and polyethylene (PE) samples were collected from Municipal Solid Waste (MSW). The process starts in the vertical-mixer wherein the crushed polymers with the appropriate ratios, are mixed at high speed using a paddle. To improve the mechanical and chemical properties of the blends, a compatibilizer called EPDM was used. The mixed material is then conveyed, in form of small pellets, to the extruder injection molding machine. After the extrusion, the specimens were prepared by injection molding.

Tensile and Flexural analysis of the blends were performed and 30PE/70PP blend showed the best mechanical properties compared to other PE/PP blends with other proportions. The addition of EPDM had a huge effect on the elongation at break but less effect on the flexural strength, the flexural modulus and the tensile strength.

This is an Open Access article distributed under the terms of the Creative Commons Attribution License

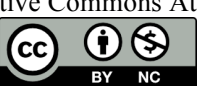

\section{References}

[1] EPA. Plastics. U.S. Environmental Protection Agency 2015.

[2] Country report on the solid waste in Lebanon. Deutsche Gesellschaft fur Internationale Zusammenarbeit (GIZ) 2014.

[3] GM Mamoor, Wahab Shahid, Amir Mushtaq, Umer Amjad, Umer Mehmood. Recycling of mixed plastics waste contain ing polyethylene, polyvinylchloride and polyethylene terephthalate, Chemical Engineering Research Bulletin 16. september 17 2013, pp. 25-30.

[4] Abdellah Ajji and Leszek Utracki, Interphase and compatibilization of polymer blends, Polymer Engineering and Science, 1996, Vol. 36.

[5] Barrel \& Screws Handbook, Ninth Edition.Reiloy Westland Corporation. 2012

[6] Chung C. I. Extrusion of Polymers: Theory and Practice. Hanser Publichers. 2000. Munich

[7] Natti Rao and Nick Schott. Understanding Plastic, Engineering Calculations. Hanser Publichers. 2000. Munich

[8] Sylvie Bertin and Jean-Jacques Robin, Study and characterization of virgin and recycled LDPE/PP blends. European Polymer Journal, November 2002, Vol. 38.

[9] Lin Jia-Horng, et al. Preparation and Compatibility Evaluation of Polypropylene/High Density Polyethylene Polyblends. Materials, 2015, Vol. 8. 8850-8859.
[10]James Scobbo and Llyod Goettler, Applications of Polymer Alloys and Blends in Polymer Blends Handbook.: Kluwer Academic, 2003. pp. 951-976.

[11] Judy Gunderson and Shannon Chilcote, Characterization of Polyethylene/Polypropylene blends. Polym Networks Blends, 1994, Vol. 4. pp. 173-181.

[12] Barlow JW and Paul DR. Mechanical properties of polypropylenelow density polyethylene. Polymer Engineering Science, 1980, Vol. 20.

[13] Teh JW. Structure and properties of polyethylene-polypropylene blend. Journal Applied Polymer Science, 1983. pp. 605-618.

[14]Jose S et al. Phase morphology,crystallisation behaviour and mechanical properties of isotactic polypropylene/high density polyethylene blends. European Polymer Journal, 2004, Vol. 40.

[15] Chang-Sik H, Hae-Dong P, Youngkyoo K, Soon-Ki K and Won-Jei C. Compatibilizer in polymer blends for the recycling of plastics waste I: Preliminary studies on $50 / 50 \mathrm{wt} \%$ virgin polyblends. Polymer Advanced Technology, 1996, Vol. 7. pp. 483-492.

[16] Si C and Chen W. Shenyang Huagong Xueyuan Xuebao.1996, Vol. 10: 65 . 
[17] Bartlett DW, Barlow JW and Paul DR. Mechanical properties of blends containing HDPE and PP. Journal of Applied Polymer Science, 1982; Vol. 27. pp. 2351-2360.

[18] Tchomakov KP, Favis BD, Huneault MA, Champagne MF and Tofan F. Mechanical properties and morphology of ternary
PP/EPDM/PE blends. Journal of Chemical Engineering, 2005, Vol. 83, pp. 300-309.

[19] Brostow W, Hagg Lobland HE and Narkis M. Sliding wear, viscoelasticity and brittleness of polymers. Journal of Materials Research, 2006 Vol. 21, Issue 9, pp. 2422-2428.

\section{Nomenclature}

$\begin{array}{ll}M S W & \text { Municipal Solid Waste } \\ P P & \text { Polypropylene } \\ P E & \text { Polyethylene } \\ L D P E & \text { Low density PE } \\ H D P E & \text { High density PE } \\ E P D M & \text { Ethylene propylene diene monomer } \\ L & \text { Lead length } \\ B & \text { Brittleness } \\ D_{b} & \text { Diameter of the barrel } \\ H & \text { Metering depth } \\ Q & \text { Plasticating ratio } \\ H & \text { Feed channel depth } \\ \theta_{b} & \text { helix angle at the barrel wall } \\ L_{t} & \text { axial length of the transition section } \\ R & \text { Compression rate } \\ C & \text { Compression ratio } \\ F . L . & \text { Flight length } \\ L_{\mathrm{f}} & \text { Feed section length } \\ L_{m} & \text { Metering section length } \\ W_{F L T} & \text { Flight width } \\ S & \text { Lead length } \\ \delta_{F L T} & \text { Flight clearance } \\ \Phi & \text { Helix angle } \\ N & \text { Speed of the screw } \\ \rho_{0} & \text { Bulk density } \\ \eta_{F} & \text { Conveying efficiency } \\ G & \text { Solid conveying rate } \\ & \end{array}$

